\title{
sciendo
}

\section{Operational risk assessment at investment funds level}

\author{
Laurentiu Paul BARANGA \\ The Bucharest University of Economic Studies, Bucharest, Romania \\ barangalp@yahoo.com
}

PICBE | 162

\begin{abstract}
The operational risk has been analysed quite recently, both by the academic environment and by financial entities in their practical activity. This new risk has recently been introduced into the "solvency models" provided by the Capital Requirement and Solvency legislation. The "solvency models" are absolute assessment models and are based on the idea of determining an optimal solvency ratio between the level of potential losses associated with the risks a financial entity is exposed to and the level of own funds it holds. Below this optimal ratio it is considered that, in the event of a materialization of the risk, the entity will go bankrupt. In the financial industry there is also a category of financial entities that legally cannot go bankrupt, at worst they may be affected by a galloping decapitalization. This category includes investment and pension funds. Due to the fact that investment and pension funds are managed externally, the operational risk originates at the level of the manager and produces its effects on the assets held by the fund, namely on the unit value of the net asset or on the value of the net asset in case of decapitalization. In order to assess the operational risk of the funds, different approaches to Capital Requirement and Solvency should be applied. In this respect, the classification of funds according to the level of risk to which they are exposed can be done through relative assessment models, and the determination of the loss amount caused by the operational risk can be done by indirect methods. Such relative risk assessment models can also be used by financial/non-financial entities that have legal personality, as a mechanism for controlling absolute assessment models, or as a stand-alone assessment methodology if there is no regulated methodology.
\end{abstract}

Keywords: operational risk, investment fund, pension fund, investment funds manager, solvency models.

\section{Introduction}

Starting with year 2000, methodologies have been developed for the assessment of the operational risk regarding financial entities who have legal personality in order to determine a potential loss (capital requirement), which should later be taken into consideration in determining the solvency/capital adequacy ratio. Such methodologies are presented in the Capital Requirement (CRD) and Solvency legislation.

In the risk management field, the solvency/capital adequacy rate establishes a ratio between the potential loss (total capital requirement) relevant to the materialization of all risks a financial entity is exposed to and the financial resources it holds (own funds). Below a certain optimal ratio of the solvency/capital adequacy rate it is considered that the financial entity is exposed to the imminent risk of going bankrupt.

In the financial industry there are also financial entities that have no legal personality and legally they cannot go bankrupt, at worst they may be affected by a galloping decapitalization. Investment and pension funds do not have legal personality, being civil societies, and are managed externally by a manager. Due to the fact that they are managed externally, the operational risk originates at the level of the manager and produces its effects on the assets held by the fund, namely on the net asset in case of decapitalization.

Any approach to assessing the operational risk for an investment fund manager may start from: a) the data published by the manager about the operational risks it is exposed to 
or that have materialized, case in which its relevant losses are known, or from b) the data published by the investment fund manager regarding the funds they manage. If, in the first situation, the approach is a direct one, in the second situation the approach is an indirect one.

Since the investment fund managers in Romania avoid publishing conclusive information and data about the existing operational risks or about those that have already materialized, an assessment of those risks cannot be made through a direct approach. That is why any solution for the assessment of operational risks by analysing the data published by managers regarding the investment funds they manage is an indirect one and, at the same time, a relative one since the agreed level of the operational risk of an investment fund is determined by considering its results in relation to the dynamics, average and median of the financial results achieved by the group of entities such fund is part of.

In other words, absolute approaches assess the risk level of the financial entity by analysing the magnitude and types of capital buffers it creates beyond the optimal level of the solvency/capital adequacy ratio, whereas relative approaches assess the risk level of the entity by considering its financial results in relation to the financial results achieved by the other financial entities that are part of the same category. This is why absolute approaches to risk assessment cannot be used for financial entities that have no legal personality because such entities are not exposed to the bankruptcy risk and also because their annual accounts do not include any accounting items composing the "own funds" indicator.

These relative risk assessment models may also be used by financial/non-financial entities that have legal personality as a mechanism for controlling absolute assessment models or as a stand-alone evaluation methodology if there is no regulated methodology.

\section{Literature review}

In the literature, there are articles dealing with the issue of investment fund evaluation, but there are presented methodologies for assessing the funds from the perspective of all risks or from the perspective of monitoring the risks and vulnerabilities existing at the level of investment funds sector Also, various materials/ articles present methods to create risk dashboards and eventually to aggregate all risks for the purpose of identifying those investment funds that prezent systemic risks.

However, there are not so many articles presenting methods for assessing potential losses registered by investment funds due to operational risks existing at the level of the manager of those funds. One of the most relevant article in this area is the „Estimating operational risk for hedge funds: The $\omega$-score” written by Stephen Brown, Willian Goetzmann, Big Liang and Christopher Schwarz and published in Financial Analysts Journal, in the first number from 2009. This is also due to the lack of relevant data on the operational risks at the level of investment fund managers as well as of the unrealized gain for the funds they manage.

Also, there are a set o regulation issued by the European Authorities (EBA, EIOPA, $\mathrm{BIS}$ ) regarding the assessment of minimum capital requirement for operational risk for some category of financial entities, such as credit institutions (CRD), investment firms (CRD), insurance/ reinsurance companies (Solvency), etc. All these regulations treat operational risk as a main factor to be considered when determining the solvency ratio or the capital adequacy ratio. 
Starting from the principles presented by the capital adequacy regulations for advanced measurement approach, other methods of determining the minimum capital requirements for operational risk have been developed. One of this methods of determining the capital requirements for operational risk is presented in the "Operational Risk Capital Models", written by Rafael Cavestany, Brenda Boultwood and Laureano F. Escudero and published in John Wiley \& Sons Journal in 2015.

PICBE | 164

\section{Methodology}

Considering that the net assets value indicator (NAV) is influenced both by the asset return and by the level of net subscriptions, in comparing the results obtained by two investment funds whose NAV level is similar, one must look not only at the dynamics of the NAV, but also at the level of net subscriptions compared to the NAV. Otherwise said, is one of the funds has negative net subscriptions and the other fund had positive net subscriptions, while their return was similar, the manager of the fund having negative net subscriptions was more performing than the manager of the fund having positive net subscriptions.

Since the performance level of a manager is influenced by factors pertaining to operational risks, such as the training level of the human resource, the quality of the IT systems and software used, the internal organization and operation, the approach to assessing the performance of a fund must also consider the net subscriptions indicator.

To that effect, in the following we will try to determine the 'true' performance achieved by a fund by also taking into account the net subscriptions indicator. After identifying the 'true' performance, we will group the data stream regarding the dynamics of the return into two areas, i.e. the very high-to-medium risk area and the average-to-very low risk area. We will consider that the operational risk level of the entities included in the second area ranges within the accepted tolerance limits. Thus, we will calculate a potential loss relevant to the operational risk only for the entities included in the first area.

Later, based on the data obtained by assessing the investment funds, we will aggregate the results of all funds managed by the same manager and, by comparing this result to the risk intervals obtained after assessing the funds, we will identify the operational risk level that the fund manager is exposed to.

In the following, we will present in detail each stage of this approach, as well as the achieved results.

\section{First stage: Creating the database}

To create a database, the largest ten investment funds of Romania have been selected, which are managed by four managers. These are open-end funds and their investment policy is mainly oriented towards financial instruments such as bonds or other debentures. Since there are open-end investment funds, investors have the option of continuously investing and disinvesting by subscribing to new units or by selling the ones already held.

Considering that the operational risks that remain unknown/are not published by the manager act as factors reducing the return of the asset portfolio held by the investment fund, the analysis contemplated, as main indicator, the net asset value (NAV) and, implicitly, the dynamics of this indicator. Since the NAV of a fund depends both on the result of financial investments and on the value of net subscriptions, the aim was to discover potential 
correlations existing between the percentage variation of the NAV (portfolio return) and the weight of net subscriptions in the NAV within a certain time interval.

To that effect, a three-year database was created, namely for the period 2016-2018, specifying, on a monthly basis, the NAV and the amount of net subscriptions for the ten investment funds. Subsequently, the monthly variation of the NAV was determined, as well as the weight of the net monthly subscriptions in the monthly NAV. For each separate indicator mentioned above, the database shows 350 observations.

The end-of-month value of the NAV indicator was chosen in order to guarantee that the variation pointed out for this indicator is the least possibly affected by the momentary evolutions of the price of financial instruments as a result of a poor liquidity of the market or because of particular and momentary conjunctures occurring in the microstructure of the market. Also, the amount of net monthly subscriptions was chosen so as to avoid being influenced by the particularities of each investment fund in terms of structure of the unit holders, as well as by any potential momentary subjective factor.

\section{Second stage}

We build a linear regression between the data pertaining to the monthly variation of the NAV and the weight of net monthly subscriptions in the NAV. The resulting equations between the monthly variation of the NAV and the weight of net monthly subscriptions in the NAV are the following: i) Weight of net subscriptions in the NAV $=0.00362476+0.016067733 * \mathrm{NAV}$ variation and ii) NAV variation $=$ (Weight of net subscriptions in the NAV 0,00362476)/0,016067733.

The regression coefficients are the following: i) R Square - 0,903191358, ii) Adjusted R Square - 0.902913172 and iii) Standard Error - 0,006781044.

\section{Third stage}

The equation obtained by regression is run, meaning that the 'true' variation of the NAV is determined by taking into account the level of net subscriptions, regardless of whether these were positive or negative. For each reporting date (monthly observation), the value of the variation determined as the 'true' NAV is subtracted from the variation of the NAV reported by the entity in order to determine the NAV variation level that was achieved in excess by the manager, but which cannot be noticed because of the negative net subscriptions, or the NAV variation level that was underachieved, but which cannot be noticed, in general, because of the positive net subscriptions. The underachieved NAV variation level is the potential loss relevant to the operational risk characterizing that particular investment fund.

\section{Table 1. Loss due to operational risk}

\begin{tabular}{|l|l|l|l|l|l|}
\hline Fund & $\begin{array}{l}\text { Reported } \\
\text { monthly } \\
\text { variation of } \\
\text { the NAV - } \\
\text { return }\end{array}$ & $\begin{array}{l}\text { Weight of net } \\
\text { subscriptions } \\
\text { in the NAV }\end{array}$ & $\begin{array}{l}\text { Monthly variation } \\
\text { of the determined } \\
\text { NAV - how much } \\
\text { the return was } \\
\text { supposed to be }\end{array}$ & $\begin{array}{l}\text { Difference between } \\
\text { the reported } \\
\text { variation and } \\
\text { determined } \\
\text { variation of the NAV }\end{array}$ & $\begin{array}{l}\text { Observations/ } \\
\text { Comments }\end{array}$ \\
\hline Fund 1 & $0.79 \%$ & $0.53 \%$ & $10.36 \%$ & $-9.56 \%$ & $\begin{array}{l}\text { Unrealized } \\
\text { return = Loss } \\
\text { due to } \\
\text { operational risk }\end{array}$ \\
\hline Fund 2 & $0.75 \%$ & $-0.11 \%$ & $-29.53 \%$ & $30.29 \%$ & \\
\hline
\end{tabular}


The values obtained for the NAV variation (obtained by subtraction) are ordered from the lowest value to the highest value. Considering that the variation of the NAV is on a monthly basis and is determined by taking into account the monthly net subscriptions, each variation of the NAV is divided to the number of business days in a given month, thus obtaining a data string ranging from $-18.7 \%$ to $27.3 \%$ regarding the (average) variation of the daily NAV.

PICBE $\mid 166$

\section{Fourth stage}

Negative extremes will be removed from the data string regarding the (average) variation of the daily NAV. At the same time, to maintain the even distribution of the data string, positive extremes will be removed as well. Thus, values up to percentile $10 \%$ and values beyond percentile $90 \%$ are removed from the data string. Later, from the resulting data string, risk level intervals pertaining to the operational risk are built as follows:

1. Risk interval from very high to high - $(-10.8 \%)-(-5.3 \%)$. The interval was determined between percentiles $1 \%$ and $25 \%$;

2. Risk interval from high to medium - $(-5.1 \%)-(-1.7 \%)$. The interval was determined between percentiles $25 \%$ and $49 \%$;

3. Medium risk - (-1.6\%) - corresponding to percentile $50 \%$

4. Risk interval from medium to low - $(-1.5 \%)-1 \%$. The interval was determined between percentiles $51 \%$ and $75 \%$;

5. Risk interval from low to very low - $1 \%-11.9 \%$. The interval was determined between percentiles $76 \%$ and $100 \%$.

It is considered that a potential loss below $1.6 \%$ is acceptable because it is within the tolerance limits described in the manager's risk policy for the relevant category of investment funds. The negative values (potential loss) exceeding this level $(-1.6 \%)$ are considered as high or very high levels of the operational risks and must be taken into account in the risk management activity.

Potential values achieved by funds outside the range going from $-10.8 \%$ to $11.9 \%$ are considered as indicative of a very high/very low risk level. The medium level of risk is determined by an value and not through an interval in order to avoid errors that may arise as a result of a lack of intervention by the risk manager because the risk lies at a tolerable level - medium risk.

\section{Fifth stage}

To determine the value of the potential loss due to the operational risk, the percentage relevant to the potential loss (determined as the difference between the reported variation and the determined variation of the NAV) must be multiplied with the value of net assets held by the relevant investment fund.

\section{Sixth stage}

To identify the operational risk level of an investment fund within a certain time interval (quarterly, biannual, annual, etc.), the simple average of the percentages relevant to the potential losses achieved by the fund during that time interval can be calculated.

Also, for a better assessment of the operational risk level within a certain time interval, the average of the percentages relevant to the potential loss, weighted by the NAV achieved by the fund during that time interval, can equally be used. For each NAV recorded 
by the fund on a reporting date, its weight in the sum of all NAVs within that time interval must be determined.

To identify the risk level of the fund during that time interval, the result achieved by the fund is compared to the aforementioned risk intervals (fourth stage).

\section{Seventh stage}

To identify the operational risk level of an investment funds manager on a certain reporting date, the simple average of the percentages relevant to the potential losses recorded by all the funds managed by that manager until such reporting date, can be used.

Also, for a better assessment of the operational risk level of an investment funds manager on a certain reporting date, the average of the percentages relevant to the potential losses achieved by such funds, weighted by the NAV held by such funds, can be used. For each NAV recorded by a fund, its weight in the sum of the NAVs relevant to the funds managed by such manager, must be determined.

To identify the risk level of the manager, the result achieved by such manager is compared to the aforementioned risk intervals (fourth stage).

\section{Eightieth stage}

To identify the risk level of an investment funds manager during a certain time interval, the simple average of the percentages relevant to the potential losses achieved by such manager during that time interval can be used.

Also, for a better assessment of the operational risk level during a certain time interval, an average of the percentages relevant to the potential losses, weighted by the NAV held by the funds managed by such manager, can also be used. For each NAV held by the funds on a certain date, its weight in the sum of the NAVs held by the funds managed by that manager during that time interval, must be determined.

To identify the risk level of the manager during that particular time interval, the result achieved by such manager is compared to the aforementioned risk intervals (fourth stage).

\section{Results and discussions}

By applying the above methodology, with little relevant data on investment funds, we were able to obtain the following categories of information regarding operational risks existing in this sector:

A. For analyzed investment funds: Operational risk level at a given date; Evolution of the operational risk level over a certain period of time; The aggregate level of operational risk over a certain period of time (quarterly); Evolution of quarterly aggregated operational risk levels; Amount of unrealized gains due to operational risks, by multiplying the the percentage relevant to the potential loss (operational risk level) with the value of net assets held by the investment fund.

Table 2 - Evolution of the operational risk level for funds over a certain period of time

\begin{tabular}{|c|c|c|c|c|c|c|c|c|c|c|}
\hline & Fund 1 & Fund 2 & Fund 3 & Fund 4 & Fund 5 & Fund 6 & Fund 7 & Fund 8 & Fund 9 & Fund 10 \\
\hline Date & Oct-17 & Oct-17 & Oct-17 & & Oct-17 & & & Oct-17 & & \\
\hline Level & $-2,2 \%$ & $5,2 \%$ & $4,9 \%$ & $5,4 \%$ & $-7,5 \%$ & $060 \%$ & $5,8 \%$ & $-1,5 \%$ & $13,5 \%$ & $6,7 \%$ \\
\hline Date & Nov-17 & Nov-17 & Nov-17 & Nov-17 & Nov-17 & Nov-17 & & Nov-17 & & Nov-17 \\
\hline Level & $-1,4 \%$ & $-11,0 \%$ & $10,5 \%$ & $14,8 \%$ & $0,7 \%$ & $4,6 \%$ & $7,3 \%$ & $-3,0 \%$ & $5,5 \%$ & $6,2 \%$ \\
\hline
\end{tabular}




\begin{tabular}{|l|l|l|l|l|l|l|l|l|l|l|} 
Date & Dec-17 & Dec-17 & Dec-17 & Dec-17 & Dec-17 & Dec-17 & Dec-17 & Dec-17 & Dec-17 & Dec-17 \\
\hline Level & $-5,9 \%$ & $0,8 \%$ & $0,8 \%$ & $1,9 \%$ & $-10,8 \%$ & $-0,4 \%$ & $1,4 \%$ & $5,5 \%$ & $11,3 \%$ & $1,9 \%$ \\
\hline Date & Jan-18 & Jan-18 & Jan-18 & Jan-18 & Jan-18 & Jan-18 & Jan-18 & Jan-18 & Jan-18 & Jan-18 \\
\hline Level & $-2,7 \%$ & $-1,8 \%$ & $2,1 \%$ & $3,4 \%$ & $-0,3 \%$ & $-0,4 \%$ & $-4,3 \%$ & $6,9 \%$ & $3,6 \%$ & $5,0 \%$ \\
\hline Date & Feb-18 & Feb-18 & Feb-18 & Feb-18 & Feb-18 & Feb-18 & Feb-18 & Feb-18 & Feb-18 & Feb-18 \\
\hline Level & $0,9 \%$ & $3,7 \%$ & $2,7 \%$ & $1,0 \%$ & $6,1 \%$ & $4,0 \%$ & $2,8 \%$ & $8,5 \%$ & $6,2 \%$ & $2,3 \%$ \\
\hline Date & Mar-18 & Mar-18 & Mar-18 & Mar-18 & Mar-18 & Mar-18 & Mar-18 & Mar-18 & Mar-18 & Mar-18 \\
\hline Level & $2,4 \%$ & $10,5 \%$ & $3,5 \%$ & $2,7 \%$ & $3,8 \%$ & $3,9 \%$ & $7,0 \%$ & $7,0 \%$ & $0,6 \%$ & $2,9 \%$ \\
\hline
\end{tabular}

Source: Authors' own research results

Color red is corresponding to a very high-to-high operational risk level; Color orange is corresponding to a high-to-average operational risk level; Color yellow is corresponding to a medium-to-low operational risk level; Color green is corresponding to a low-to-very low operational risk level.

Table 3 - Evolution of quarterly aggregated operational risk levels for investment funds

\begin{tabular}{|c|c|c|c|c|c|c|c|c|c|c|}
\hline $\begin{array}{l}\text { ID } \\
\text { Fund }\end{array}$ & $\begin{array}{l}\text { Fund } \\
1\end{array}$ & $\begin{array}{l}\text { Fund } \\
2\end{array}$ & $\begin{array}{l}\text { Fund } \\
3\end{array}$ & $\begin{array}{l}\text { Fund } \\
4\end{array}$ & $\begin{array}{l}\text { Fund } \\
5\end{array}$ & $\begin{array}{l}\text { Fund } \\
6 \\
\end{array}$ & $\begin{array}{l}\text { Fund } \\
7\end{array}$ & $\begin{array}{l}\text { Fund } \\
8\end{array}$ & $\begin{array}{l}\text { Fund } \\
9\end{array}$ & $\begin{array}{l}\text { Fund } \\
10\end{array}$ \\
\hline Interv. & Q4/17 & $\mathrm{Q} 4 / 17$ & Q4/17 & Q4/17 & Q4/17 & $\mathrm{Q} 4 / 17$ & Q4/17 & Q4/17 & $\mathrm{Q} 4 / 17$ & Q4/17 \\
\hline Level & $-3,2 \%$ & $-1,7 \%$ & $5,4 \%$ & $7,4 \%$ & $-5,9 \%$ & $1,2 \%$ & $4,8 \%$ & $0,3 \%$ & $10,1 \%$ & $4,9 \%$ \\
\hline Interv. & Q1/18 & $\mathrm{Q} 1 / 18$ & Q1/18 & Q1/18 & Q1/18 & Q1/18 & Q1/18 & Q1/18 & Q1/18 & Q1/18 \\
\hline Level & $0,2 \%$ & $4,1 \%$ & $2,8 \%$ & $2,4 \%$ & $3,2 \%$ & $2,5 \%$ & $1,8 \%$ & $7,4 \%$ & $3,4 \%$ & $3,4 \%$ \\
\hline Interv. & $\mathrm{Q} 2 / 18$ & $\mathrm{Q} 2 / 18$ & Q2/18 & Q2/18 & $\mathrm{Q} 2 / 18$ & Q2/18 & Q2/18 & Q2/18 & $\mathrm{Q} 2 / 18$ & Q2/18 \\
\hline Level & $3,5 \%$ & $1,3 \%$ & $7,0 \%$ & $6,0 \%$ & $6,4 \%$ & $6,7 \%$ & $3,6 \%$ & $7,7 \%$ & $7,7 \%$ & $6,4 \%$ \\
\hline Interv. & Q3/18 & Q3/18 & Q3/18 & Q3/18 & Q3/18 & Q3/18 & Q3/18 & Q3/18 & Q3/18 & Q3/18 \\
\hline Level & $4,0 \%$ & $1,1 \%$ & $4,7 \%$ & $5,6 \%$ & $10,3 \%$ & $3,1 \%$ & $4,2 \%$ & $7,2 \%$ & $8,5 \%$ & $4,3 \%$ \\
\hline
\end{tabular}

Source: Authors' own research results

Color red is corresponding to a very high-to-high operational risk level; Color orange is corresponding to a high-to-average operational risk level; Color yellow is corresponding to a medium-to-low operational risk level; Color green is corresponding to a low-to-very low operational risk level.

B. For investment funds managers: Operational risk level at a given date; Evolution of the operational risk level over a certain period of time; The aggregate level of operational risk over a certain period of time; Evolution of annual aggregate operational risk levels.

Table 4 - The aggregate level of operational risk over a certain period of time for investment funds manager

\begin{tabular}{|l|l|l|l|l|}
\hline ID Manager & Manager A & Manager B & Manager C & Manager D \\
\hline Interval & $2016-2018$ & $2016-2018$ & $2016-2018$ & $2016-2018$ \\
\hline Operational risk level & $2.5 \%$ & $-1.7 \%$ & $2.7 \%$ & $2.2 \%$ \\
\hline
\end{tabular}

Manager A achieved a risk value of $2.5 \%$ - corresponding to a low-to-very low operational risk level; Manager B achieved a risk value of (-1.7\%) - corresponding to a highto-average operational risk level; Manager $\mathrm{C}$ achieved a risk value of $2.7 \%$ - corresponding to a low-to-very low operational risk level; Manager D achieved a risk value of $2.2 \%$ corresponding to a low-to-very low operational risk level. 
Table 5 - Evolution of annual aggregate operational risk levels for investment funds

managers

\begin{tabular}{|l|l|l|l|l|}
\hline ID Manager & Manager A & Manager B & Manager C & Manager D \\
\hline Year & 2016 & 2016 & 2016 & 2016 \\
\hline Operational risk level & $3,1 \%$ & $-7,8 \%$ & $1,1 \%$ & $1,2 \%$ \\
\hline Year & 2017 & 2017 & 2017 & 2017 \\
\hline Operational risk level & $-0,1 \%$ & $-2,5 \%$ & $1,5 \%$ & $1,3 \%$ \\
\hline Year & 2018 & 2018 & 2018 & 2018 \\
\hline Operational risk level & $4,5 \%$ & $5,9 \%$ & $5,6 \%$ & $4,4 \%$ \\
\hline
\end{tabular}

PICBE | 169

Color red is corresponding to a very high-to-high operational risk level; Color orange is corresponding to a high-to-average operational risk level; Color yellow is corresponding to a medium-to-low operational risk level; Color green is corresponding to a low-to-very low operational risk level.

\section{Conclusions}

\section{This approach to assessing the operational risk has a number of advantages}

It may be used when investment funds managers fail to publish data and information about the existing operational risks pertaining to such funds, or operational risks that materialized in the past (there is no sufficient data and information to assess the operational risk).

Also, may be used for assessing both the operational risk pertaining to an investment fund and the operational risk pertaining to the manager of that fund. The assessment of the operational risk pertaining to a fund is useful when the management of that fund is ensured by one of the manager's department.

By using this approach to assessing the operational risk, the operational risk of the investment funds/managers of funds at an aggregated level can be assessed, and the aggregated potential loss (due to using unsuitable human resources and unsuitable IT systems and software, as well as due to the lack of an efficient internal organization at administrator level).

This approach to assessing the operational risk may be used for assessing the operational risk both at individual level (at microlevel) and at the investment funds industry level (at macrolevel), being easily adaptable on a case by case basis, by taking into account other factors or conjunctures as well. In the event that several indicators are to be taken into account in assessing the operational risk, to determine an equation between the NAV variation and other indicators, the Principal Component Analysis (PCA) method may also be used.

Also, this approach may be used by financial/non-financial entities that have legal personality (e.g.: credit institutions, insurance companies etc.), as a mechanism for controlling absolute assessment methods, or as a stand-alone assessment methodology if there is no regulated methodology.

\section{This approach to assessing the operational risk has a number of limitations}

The results of this approach to assessing the operational risk must be interpreted by taking into account aspects regarding the investment funds manager's policy in managing the liquidity risk pertaining to each investment fund, such as: the level of highly liquid assets for 
each maturity range, the capacity of restructuring the asset portfolio held by the investment fund within a certain time horizon, etc.

Using this approach, the potential loss relevant to the operational risk cannot be broken down by various criteria, such as: areas of the operational risk, activities, processes or activity lines. In other words, the operational risk of the investment funds/managers of funds can be assessed at an aggregated level.

PICBE | 170

\section{References}

Iulian Panait, Laurentiu Paul Baranga (2018). A risk assessment framework for alternative investment funds, both at fund level and market level. Financial Studies No. 2/22. Retrieved from http://www.icfm.ro/fs.icfm.ro/P2.FS2.2018.pdf.

Blancher, N., Mitra, S., Morsy, H., Otani, A., Severo, T. and 1. Valderrama, L. (2013). Systemic Risk Monitoring ('SysMo') Toolkit - A User Guide. IMF Working Paper No. 13/168. Retrieved from https://ssrn.com/abstract=2307411.

Doyle, N., Hermans, L., Molitor, P.A.M. and Weistroffer, C. 2. (2016). Shadow Banking in the Euro Area: Risks and Vulnerabilities in the Investment Fund Sector. ECB Occasional Paper No. 174. Retrieved from https://ssrn.com/abstract=2804616.

Eppler, M., Aeschimann, M. (2009). A systematic framework for risk visualization in risk management and communication. Risk Management, vol.11, issue 2, pp.67-89

Huang, W., Menkveld, A. J., (2016). Systemic Risk in Real Time: A Risk Dashboard for Central Clearing Parties (CCPS). Retrieved from https://ssrn.com/abstract=2886167.

Stephen Brown, Willian Goetzmann, Big Liang și Christopher Schwarz (2009). Estimating operational risk for hedge funds: The $\omega$-score. Financial Analysts Journal, vol. 1 from 2009.

Rafael Cavestany, Brenda Boultwood și Laureano F. Escudero (2015). Operational Risk Capital Models, John Wiley \& Sons Journal.

***European Banking Authority (2018) 'Risk Dashboard'. Retrieved from http://www.eba.europa.eu/risk-analysisand-data/risk-dashboard.

*** European Securities and Markets Authorities (2018) 'Risk Dashboard'. Retrieved from https://www.esma.europa.eu/market-analysis/financialstability.

***European Systemic Risk Board (2018) 'Risk Dashboard', Retrieved from http://www.esrb.europa.eu/pub/rd/html/index.en.html. 